\title{
Beta-blockers utilization in heart failure patients: Sub-analysis of a nation-wide population-based study in the Czech Republic
}

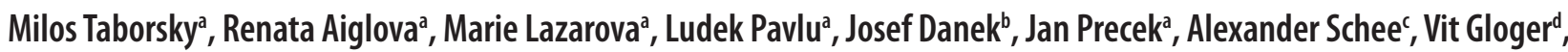 \\ Marek Vicha ${ }^{a}$, Tomas Skala ${ }^{a}$
}

\begin{abstract}
Aims. Sub-analysis of a retrospective nation-wide observational analysis of heart failure (HF) epidemiology reported to the Czech National Registry of Reimbursed Health Services between 2012 and 2018 aimed at beta-blockers (BBs) utilization.

Methods and Results. The beta-blockers were generally used in $81.8 \%$ of all patients treated for HF in 2012 ( $n=52140)$; $81.8 \%$ in 2013 ( $n=53$ 058); 83.1\% in 2014 ( $n=56221) ; 82.1 \%$ in 2015 ( $n=57421) ; 83.3 \%$ in 2016 ( $n=59187) ; 82.2 \%$ in 2017 (60 058) and in $81.4 \%$ in 2018 ( $n=60$ 966). In 2018, the majority of patients treated for HF were prescribed metoprolol (22 974; 30.7\%) and bisoprolol (21 001; 28\%). Carvedilol was prescribed in 7331 patients treated for HF (9.8\%), nebivolol in $5392 \mathrm{HF}$ patients. Despite its primary indication, betaxolol was used in 2341 patients treated for HF (3.1\%). All other beta-blockers were used in less than $1 \%$ of HF patients. In some of the mostly used BBs, their prescription in patients treated for HF changed in the last years (metoprolol 32.4\% in 2012, 30.7\% in 2018; bisoprolol 20.3\% in 2012, 28\% in 2018; carvedilol 18.3\% in 2012, 9.8\% in 2018; nebivolol 2.5\% in 2012, 7.2\% in 2018; betaxolol 4.2\% in 2012, 3.1\% in 2018). Conclusion. In an analysis of beta-blockers utilization in all patients treated for heart failure in the given year in the whole country, we have found only slightly lower amount of drug prescription in comparison with specific heart failure registries. This indicates a good translation of current standard of care into common clinical practice. Metoprolol remained the mostly prescribed drug. The prescription of bisoprolol and nebivolol has increased at the expense of carvedilol.
\end{abstract}

Key words: beta-blockers, heart failure, treatment

Received: September 6, 2020; Revised: November 11, 2020; Accepted: November 20, 2020; Available online: December 15, 2020 https://doi.org/10.5507/bp.2020.057

(c) 2021 The Authors; https://creativecommons.org/licenses/by/4.0/

aDepartment of Internal Medicine I - Cardiology, University Hospital Olomouc, 775 20 Olomouc, Czech Republic

${ }^{b}$ Department of Internal Medicine, Military University Hospital, Prague, Czech Republic

'Cardio center, Regional Hospital Karlovy Vary, Karlovy Vary, Czech Republic

${ }^{d}$ Bata's Regional Hospital, Zlin, Czech Republic

Corresponding author: Tomas Skala, e-mail: tomasskala@gmail.com

\section{INTRODUCTION}

Heart failure (HF) still poses a major global public health challenge. Beta-blockers (BBs) were shown to have highly positive effects in patients with HF and they have become a cornerstone in its treatment. The mechanisms by which BBs exert benefit in HF patients are uncertain ${ }^{1}$. Blocking adrenergic receptors reduces heart rate and alters vascular function. It also has a direct effect on cardiomyocytes, and modifies the neuro-endocrine response to HF (ref. ${ }^{2}$ ). The importance of these mechanisms may vary by etiology of $\mathrm{HF}$, heart rhythm and clinical indication of BBs utilization. In patients with $\mathrm{HF}$ with reduced ejection fraction (HFrEF) in sinus rhythm (SR), BBs improve LV systolic function and reduce mortality ${ }^{3}$. Benefits of BBs also apply for patients with a mid-range ejection fraction (HFmrEF) in SR ( ref. $^{3}$ ). Too few patients have been studied in RCTs to evaluate efficacy and safety of BBs in HFpEF patients. In HF patients with concomitant AF, no prognostic benefit of BBs was seen. If this evidence translates to BBs utilization in common clinical practice is not known. Considering utilization of BBs in $\mathrm{HF}$ patients, we have data from several HF registries in the Czech Republic but no registry evaluated all HF patients in the whole country ${ }^{4,5}$. It is unknown if observations from within-registry analyses can be extrapolated to non-enrolled patients. We can anticipate more frequent utilization of novel up-to-date evidence-based diagnostic and treatment strategies in hospitals involved in HF registries $^{6}$. This can be potentially associated with a better outcome of enrolled patients. Differences in the case-mix of the registries, age and gender distributions, and comorbidities of the participants, can influence interpretation of the results. To obtain nationwide data on HF we analyzed data from the Czech National Registry of Reimbursed Health Services which contains a complete dataset of medical claims to all health insurance companies operating within the country. Of note, only few countries have reported nationwide trends in the epidemiology of $\mathrm{HF}$ and almost no data are available from the former Eastern bloc countries. Therefore, results of this study might be important for the planning of health expenditures, clinical research and selection of countries for clinical trials. 
Table 1. Baseline epidemiological characteristics of HF patients.

\begin{tabular}{lccccccc}
\hline Prevalence & 2012 & 2013 & 2014 & 2015 & 2016 & 2017 & 2018 \\
\hline All & 176496 & 202135 & 223808 & 243683 & 256929 & 271907 & 285745 \\
$\geq 65$ years & 141441 & 162813 & 180990 & 198075 & 209339 & 222482 & 234120 \\
Male gender & 88591 & 101576 & 112330 & 122566 & 129867 & 137642 & 145297 \\
\hline
\end{tabular}

\section{Study aim}

The aim of this study is to analyze individual types of BBs in all HF patients in the whole country in recent years and to compare these data with the currently available guidelines for the treatment of HF patients ${ }^{7,8}$.

\section{METHODS}

\section{Study design}

This is a pharmacological sub-study of a retrospective observational analysis of diagnoses, procedures and treatment reported to the Czech National Registry of Reimbursed Health Services (NRRHS) between 2010 and 2018. The main time period used in the study was 20122018; time period 2010-2011 was included as a medical history of patients only.

\section{Patients' selection definition, data extraction and study timeline}

The patients' cohort was selected based on the International Classification of Diseases (ICD-10) data. All patients with I50.x diagnosis code was selected and considered as patients with HF. Only the first HF diagnosis per single patient was taken into account. The data obtained from NRRHS include both in-patient and out-patient departments. All data were obtained in accordance with the national law and policy as anonymized results of pre-specified analyses. Data were anonymized before the linked database was released to the research group. Since this was a retrospective, anonymized study and the data are collected according to law no. 372/2011 about healthcare services, no informed consent was required.

The medical history of all HF patients was assessed, and all comorbidities recorded during 2010-2018 period. The pharmacotherapy was evaluated separately for individual types of BBs.

\section{Patients "with HF" and "Treated for HF"}

Patients "with HF" were all patients that had an I50.x ICD diagnosis code accounted for in any given year (20102018).

Patients were considered as "Treated for HF" if a medical procedure and/or examination at an in- out-patient department using an I50.x ICD diagnosis code were accounted for in the given year.

\section{RESULTS}

Prevalence of HF patients, their age and gender are depicted in Table 1. There were 176496 patients with HF in
2012 (out of 10.51 million citizens of the Czech Republic in 2012). Number of these patients grew constantly. In 2018 (10.65 million citizens of the Czech Republic in 2018), there were 285745 patients with HF (mean age $74.4 \pm 12.8$ ); slightly more men (145 297; mean age 71.5 \pm 12.5 ) than women (140 432; mean age $77.4 \pm 12.3)$. The majority of HF patients were older than 70 years $(70.4 \%)$.

Comorbidities in HF patients in 2018 are summarized in Table 2. Cardiovascular and oncological diseases were common in HF patients. In 2018, the most prevalent were arterial hypertension (92.6\% of all HF patients) and coronary artery disease (77.9\% of all HF patients). Moreover, $62.8 \%$ of HF patients in 2018 had a history of arrhythmias, $49.7 \%$ of them had a history of AF. Diabetes mellitus (41\%) and hyperlipoproteinemia (49.6\%) were also highly prevalent. Oncological disease was present in $23.6 \%$ of patients.

The beta-blockers were generally used in $70.8 \%$ of all HF patients in $2012(n=124887) ; 70.1 \%$ in $2013(n=141$ $724) ; 70.7 \%$ in $2014(\mathrm{n}=158282) ; 70.0 \%$ in $2015(\mathrm{n}=170$ $647) ; 70.4 \%$ in $2016(n=180807) ; 69.6 \%$ in $2017(n=189$ $127)$ and in $68.8 \%$ in $2018(n=196452)$.

The beta-blockers were generally used in $81.8 \%$ of all patients treated for HF in $2012(n=52140) ; 81.8 \%$ in 2013 $(\mathrm{n}=53058) ; 83.1 \%$ in $2014(\mathrm{n}=56221) ; 82.1 \%$ in 2015

Table 2. Comorbidities in HF patients in 2018.

\begin{tabular}{lrc}
\hline & \multicolumn{2}{c}{$\begin{array}{c}\text { all HF } \\
\text { patients } \\
(\%)\end{array}$} \\
\hline Arterial hypertension & 264499 & 92.6 \\
Coronary artery disease & 222585 & 77.9 \\
Acute myocardial infarction & 44100 & 15.4 \\
Valve disease & 85611 & 30.0 \\
Cardiomyopathy & 28487 & 10.0 \\
Arrhythmias & 179576 & 62.8 \\
Atrial fibrillation & 141988 & 49.7 \\
Stroke & 50266 & 17.6 \\
Cancer & 67393 & 23.6 \\
Diabetes mellitus & 117265 & 41.0 \\
Dyslipoproteinemias & 141764 & 49.6 \\
Chronic obstructive pulmonary disease & 91052 & 31.9 \\
Sleep apnea & 7664 & 2.7 \\
Renal failure & 73998 & 25.9 \\
Dementia & 34534 & 12.1 \\
Alzheimer's disease & 17010 & 6.0 \\
\hline
\end{tabular}


Table 3A. Individual types of BBs in all HF patients.

\begin{tabular}{|c|c|c|c|c|c|c|c|c|c|c|c|c|c|c|}
\hline \multirow[b]{2}{*}{ Beta-blocker type } & \multicolumn{2}{|c|}{2012} & \multicolumn{2}{|c|}{2013} & \multicolumn{2}{|c|}{2014} & \multicolumn{2}{|c|}{2015} & \multicolumn{2}{|c|}{2016} & \multicolumn{2}{|c|}{2017} & \multicolumn{2}{|c|}{2018} \\
\hline & $\begin{array}{c}\text { Number } \\
\text { treated }\end{array}$ & $\begin{array}{c}\% \text { of } \\
\text { prevalence }\end{array}$ & $\begin{array}{c}\text { Number } \\
\text { treated }\end{array}$ & $\begin{array}{c}\% \text { of } \\
\text { prevalence }\end{array}$ & $\begin{array}{c}\text { Number } \\
\text { treated }\end{array}$ & $\begin{array}{c}\% \text { of } \\
\text { prevalence }\end{array}$ & $\begin{array}{c}\text { Number } \\
\text { treated }\end{array}$ & $\begin{array}{c}\% \text { of } \\
\text { prevalence }\end{array}$ & $\begin{array}{c}\text { Number } \\
\text { treated }\end{array}$ & $\begin{array}{c}\% \text { of } \\
\text { prevalence }\end{array}$ & $\begin{array}{c}\text { Number } \\
\text { treated }\end{array}$ & $\begin{array}{c}\% \text { of } \\
\text { prevalence }\end{array}$ & $\begin{array}{c}\text { Number } \\
\text { treated }\end{array}$ & $\begin{array}{c}\% \text { of } \\
\text { prevalence }\end{array}$ \\
\hline SOTALOL & 1202 & 0.7 & 1282 & 0.6 & 1413 & 0.6 & 1487 & 0.6 & 1558 & 0.6 & 1546 & 0.6 & 1622 & 0.6 \\
\hline METOPROLOL & 52711 & 29.9 & 60256 & 29.8 & 67479 & 30.2 & 72134 & 29.6 & 75754 & 29.5 & 77882 & 28.6 & 79335 & 27.8 \\
\hline ATENOLOL & 2104 & 1.2 & 2114 & 1.0 & 2141 & 1.0 & 2052 & 0.8 & 1937 & 0.8 & 1907 & 0.7 & 1787 & 0.6 \\
\hline ACEBUTOLOL & 1876 & 1.1 & 1965 & 1.0 & 2091 & 0.9 & 1982 & 0.8 & 2000 & 0.8 & 1872 & 0.7 & 1725 & 0.6 \\
\hline BISOPROLOL & 30998 & 17.6 & 36243 & 17.9 & 41327 & 18.5 & 46382 & 19.0 & 51969 & 20.2 & 58107 & 21.4 & 64655 & 22.6 \\
\hline CELIPROLOL & 669 & 0.4 & 656 & 0.3 & 668 & 0.3 & 603 & 0.2 & 591 & 0.2 & 538 & 0.2 & 527 & 0.2 \\
\hline NEBIVOLOL & 3329 & 1.9 & 6361 & 3.1 & 9802 & 4.4 & 12587 & 5.2 & 14518 & 5.7 & 16097 & 5.9 & 17107 & 6.0 \\
\hline KARVEDILOL & 23811 & 13.5 & 23994 & 11.9 & 23794 & 10.6 & 23029 & 9.5 & 21763 & 8.5 & 20258 & 7.5 & 18841 & 6.6 \\
\hline $\begin{array}{l}\text { BISOPROLOL and } \\
\text { THIAZIDES }\end{array}$ & 463 & 0.3 & 550 & 0.3 & 588 & 0.3 & 626 & 0.3 & 647 & 0.3 & 540 & 0.2 & 486 & 0.2 \\
\hline NEBIVOLOL and THIAZIDES & 3 & 0.0 & 15 & 0.0 & 0 & 0.0 & 0 & 0.0 & 0 & 0.0 & 0 & 0.0 & 0 & 0.0 \\
\hline $\begin{array}{l}\text { BISOPROLOL and other } \\
\text { antihypertensive drugs }\end{array}$ & 133 & 0.1 & 254 & 0.1 & 322 & 0.1 & 557 & 0.2 & 732 & 0.3 & 930 & 0.3 & 967 & 0.3 \\
\hline BOPINDOLOL & 0 & 0.0 & 0 & 0.0 & 0 & 0.0 & 0 & 0.0 & 0 & 0.0 & 0 & 0.0 & 0 & 0.0 \\
\hline BETAXOLOL & 7227 & 4.1 & 7672 & 3.8 & 8253 & 3.7 & 8736 & 3.6 & 8899 & 3.5 & 9055 & 3.3 & 9018 & 3.2 \\
\hline ESMOLOL & 1 & 0.0 & 0 & 0.0 & 14 & 0.0 & 17 & 0.0 & 21 & 0.0 & 12 & 0.0 & 9 & 0.0 \\
\hline $\begin{array}{l}\text { BISOPROLOL } \\
\text { in a combination }\end{array}$ & 0 & 0.0 & 0 & 0.0 & 14 & 0.0 & 66 & 0.0 & 55 & 0.0 & 1 & 0.0 & 0 & 0.0 \\
\hline LABETALOL & 0 & 0.0 & 0 & 0.0 & 0 & 0.0 & 1 & 0.0 & 0 & 0.0 & 0 & 0.0 & 0 & 0.0 \\
\hline ATENOLOL and THIAZIDES & 360 & 0.2 & 362 & 0.2 & 376 & 0.2 & 388 & 0.2 & 363 & 0.1 & 382 & 0.1 & 373 & 0.1 \\
\hline $\begin{array}{l}\text { Prevalence of patients with } \\
\text { heart failure }\end{array}$ & 176496 & & 202135 & & 223808 & & 243683 & & 256929 & & 271907 & & 285745 & \\
\hline All beta-blockers & 124887 & $70.8 \%$ & 141724 & $70.1 \%$ & 158282 & $70.7 \%$ & 170647 & $70.0 \%$ & 180807 & $70.4 \%$ & 189127 & $69.6 \%$ & 196452 & $68.8 \%$ \\
\hline
\end{tabular}

Table 3B. Individual types of BBs in patients treated for HF.

\begin{tabular}{|c|c|c|c|c|c|c|c|c|c|c|c|c|c|c|}
\hline \multirow[b]{2}{*}{ Beta-blocker type } & \multicolumn{2}{|c|}{2012} & \multicolumn{2}{|c|}{2013} & \multicolumn{2}{|c|}{2014} & \multicolumn{2}{|c|}{2015} & \multicolumn{2}{|c|}{2016} & \multicolumn{2}{|c|}{2017} & \multicolumn{2}{|c|}{2018} \\
\hline & $\begin{array}{c}\text { Number } \\
\text { treated }\end{array}$ & $\begin{array}{c}\% \text { of } \\
\text { prevalence }\end{array}$ & $\begin{array}{c}\text { Number } \\
\text { treated }\end{array}$ & $\begin{array}{c}\% \text { of } \\
\text { prevalence }\end{array}$ & $\begin{array}{l}\text { Number } \\
\text { treated }\end{array}$ & $\begin{array}{c}\% \text { of } \\
\text { prevalence }\end{array}$ & $\begin{array}{c}\text { Number } \\
\text { treated }\end{array}$ & $\begin{array}{c}\% \text { of } \\
\text { prevalence }\end{array}$ & $\begin{array}{l}\text { Number } \\
\text { treated }\end{array}$ & $\begin{array}{c}\% \text { of } \\
\text { prevalence }\end{array}$ & $\begin{array}{c}\text { Number } \\
\text { treated }\end{array}$ & $\begin{array}{c}\% \text { of } \\
\text { prevalence }\end{array}$ & $\begin{array}{c}\text { Number } \\
\text { treated }\end{array}$ & $\begin{array}{c}\% \text { of } \\
\text { prevalence }\end{array}$ \\
\hline SOTALOL & 419 & 0.7 & 390 & 0.6 & 446 & 0.7 & 423 & 0.6 & 423 & 0.6 & 421 & 0.6 & 420 & 0.6 \\
\hline METOPROLOL & 20666 & 32.4 & 21033 & 32.4 & 22403 & 33.1 & 22720 & 32.5 & 23236 & 32.7 & 23069 & 31.6 & 22974 & 30.7 \\
\hline ATENOLOL & 783 & 1.2 & 736 & 1.1 & 663 & 1.0 & 604 & 0.9 & 587 & 0.8 & 529 & 0.7 & 469 & 0.6 \\
\hline ACEBUTOLOL & 673 & 1.1 & 668 & 1.0 & 652 & 1.0 & 558 & 0.8 & 537 & 0.8 & 475 & 0.7 & 421 & 0.6 \\
\hline BISOPROLOL & 12949 & 20.3 & 13567 & 20.9 & 14575 & 21.5 & 15670 & 22.4 & 17391 & 24.5 & 19139 & 26.2 & 21001 & 28.0 \\
\hline CELIPROLOL & 274 & 0.4 & 241 & 0.4 & 213 & 0.3 & 169 & 0.2 & 161 & 0.2 & 140 & 0.2 & 127 & 0.2 \\
\hline NEBIVOLOL & 1616 & 2.5 & 2783 & 4.3 & 4098 & 6.1 & 4673 & 6.7 & 5082 & 7.2 & 5289 & 7.2 & 5392 & 7.2 \\
\hline KARVEDILOL & 11678 & 18.3 & 10738 & 16.6 & 10217 & 15.1 & 9583 & 13.7 & 8803 & 12.4 & 7998 & 11.0 & 7331 & 9.8 \\
\hline $\begin{array}{l}\text { BISOPROLOL and } \\
\text { THIAZIDES }\end{array}$ & 182 & 0.3 & 189 & 0.3 & 169 & 0.2 & 185 & 0.3 & 194 & 0.3 & 151 & 0.2 & 135 & 0.2 \\
\hline NEBIVOLOL and THIAZIDES & 3 & 0.0 & 9 & 0.0 & 0 & 0.0 & 0 & 0.0 & 0 & 0.0 & 0 & 0.0 & 0 & 0.0 \\
\hline $\begin{array}{l}\text { BISOPROLOL and other } \\
\text { antihypertensive drugs }\end{array}$ & 59 & 0.1 & 87 & 0.1 & 106 & 0.2 & 172 & 0.2 & 228 & 0.3 & 276 & 0.4 & 244 & 0.3 \\
\hline BOPINDOLOL & 0 & 0.0 & 0 & 0.0 & 0 & 0.0 & 0 & 0.0 & 0 & 0.0 & 0 & 0.0 & 0 & 0.0 \\
\hline BETAXOLOL & 2695 & 4.2 & 2473 & 3.8 & 2545 & 3.8 & 2511 & 3.6 & 2417 & 3.4 & 2455 & 3.4 & 2341 & 3.1 \\
\hline ESMOLOL & 0 & 0.0 & 0 & 0.0 & 7 & 0.0 & 10 & 0.0 & 11 & 0.0 & 7 & 0.0 & 4 & 0.0 \\
\hline $\begin{array}{l}\text { BISOPROLOL in a } \\
\text { combination }\end{array}$ & 0 & 0.0 & 0 & 0.0 & 2 & 0.0 & 18 & 0.0 & 9 & 0.0 & 0 & 0.0 & 0 & 0.0 \\
\hline ATENOLOL and THIAZIDES & 143 & 0.2 & 144 & 0.2 & 125 & 0.2 & 125 & 0.2 & 108 & 0.2 & 109 & 0.1 & 107 & 0.1 \\
\hline $\begin{array}{l}\text { Prevalence of patients with } \\
\text { heart failure }\end{array}$ & 63714 & & 64856 & & 67685 & & 69927 & & 71045 & & 73026 & & 74885 & \\
\hline All beta-blockers & 52140 & $81.8 \%$ & 53058 & $81.8 \%$ & 56221 & $83.1 \%$ & 57421 & $82.1 \%$ & 59187 & $83.3 \%$ & 60058 & $82.2 \%$ & 60966 & $81.4 \%$ \\
\hline
\end{tabular}

$(\mathrm{n}=57421) ; 83.3 \%$ in $2016(\mathrm{n}=59$ 187); 82.2\% in 2017 (60 058) and in 81.4\% in 2018 ( $n=60$ 966).

Individual types of BBs are depicted in Table $3 \mathrm{~A}$ (all HF patients) and Table 3B (patients treated for HF).

In 2018, the majority of patients treated for HF were prescribed metoprolol (22 974; 30.7\%) and bisoprolol (21 001; 28\%). Carvedilol was prescribed in 7331 patients treated for HF (9.8\%), nebivolol in $5392 \mathrm{HF}$ patients. Despite its primary indication, betaxolol was used in 2341 patients treated for HF (3.1\%). All other betablockers were used in less than $1 \%$ of HF patients.

In some of the mostly used BBs their prescription in patients treated for HF changed in the last years (metoprolol $32.4 \%$ in $2012,30.7 \%$ in 2018 ; bisoprolol $20.3 \%$ in $2012,28 \%$ in 2018 ; carvedilol $18.3 \%$ in $2012,9.8 \%$ in 2018 ; nebivolol $2.5 \%$ in $2012,7.2 \%$ in 2018 ; betaxolol $4.2 \%$ in $2012,3.1 \%$ in 2018). 


\section{DISCUSSION}

We have retrospectively evaluated the utilization of BBs in all HF patients in the Czech Republic ( $\mathrm{n}=10.6$ million in 2018) that were examined in either in-patient or out-patient department and had an established diagnosis of HF regardless of its type, severity, treatment or date of onset ( $\mathrm{n}=285745$ in 2018). The beta-blockers were used in less than $70 \%$ of HF patients. The majority of HF patients were prescribed metoprolol and bisoprolol. Nebivolol and carvedilol were used far less often. Despite its primary indication, betaxolol was used in almost a comparable number of patients as nebivolol and carvedilol. All other BBs were used in less than $1 \%$ of HF patients. Metoprolol remained the mostly prescribed drug. The prescription of bisoprolol and nebivolol increased at the expense of carvedilol. Since we were analyzing data from all patients of the entire country, the case-mix is different than in the HF registries performed usually in specialized centers 9 . The external validity of outcome of patients in specific HF registries is limited because of selectivity of individual hospitals and/or patients' participation. When compared to the FAR-NHL registry of Czech chronic HF patients with $93.8 \%$ of chronic HF patients on BBs, there is an evident under-treatment when compared to a sought-after standard of care ${ }^{4}$. The explanation of this under-treatment compared with the registries could be the fact that patients in the analyzed population are added successively. This means that patients treated for HF in 2012 are still included in the analyzed population of HF patients in 2018 if they are still alive even if they are not treated for HF anymore. In the long run, it seems that the BBs utilization decreases when compared to HF registries. Thus, we have analyzed the BBs use in patients Treated for HF in the given year (see the definition above). This analysis is more comparable to the HF registries that include patients with an episode of HF in the given year or at least examined or treated for the HF in the given year. When a Treated for HF analysis was used and all types of BBs were included, the percentage of BBs use was far more comparable with the HF registries (81.8\% of patients in 2012; $81.4 \%$ in 2018 vs $93.8 \%$ in the FAR-NHL registry) $\left(\right.$ ref. $\left.{ }^{4}\right)$. Moreover, data from FAR-NHL registry represent patients treated in a specialized CV center but the majority of patients are treated in out-patient departments. A large number of patients in our database diminishes the chance of selection bias. On the other hand, it inevitably leads to a low detail of individual patients' data. Data from echocardiography, including left ventricle ejection fraction (LVEF), ECG and laboratory samples are missing entirely. We thus cannot specify the severity of HF based on LVEF in our patients. BBs are indicated for the treatment of a vast spectrum of HF patients but current evidence shows that their benefit on the outcome of HF patients differs based on LVEF, type of cardiomyopathy and presence of AF. In HFrEF patients in SR, BBs increase LVEF and reduce mortality and are clearly indicat$\mathrm{ed}^{1}$. According to a subgroup analysis of the MERIT-HF trial, the lower the LVEF, the higher the benefit of BBs was present ${ }^{10}$. A meta-analysis of all the major BBs trials in HFrEF patients showed no mortality benefit in HFrEF patients with $\mathrm{AF}$ (ref. $\left.{ }^{11}\right)$. However, BBs did not increase the risk, and they should be considered for rate control in HFrEF patients with AF, especially in those with high heart rate. In patients with HF with mid-range ejection fraction (HFmrEF) and/or HF with preserved ejection fraction (HFpEF), prospective clinical trials are scarce and most often have indirect endpoints and a small sample size that precludes evaluation of clinical endpoints ${ }^{12,13}$. In a recent analysis of $11 \mathrm{HF}$ trials, BBs reduced the risk of all-cause and cardiovascular (CV) death in a subgroup of 575 patients with LVEF 40-49\% (HFmrEF) in SR. LVEF increased with BBs in all groups, except those with LVEF $>50 \%$. The effect of BBs on mortality in patients with LVEF $40-49 \%$ is similar to that observed with LVEF $<40 \%\left(\right.$ ref. $\left.^{3}\right)$. Based on these facts, an expert-consensus recommendation for BBs use in HFmrEF patients is that BBs may be considered for ambulatory patients with symptomatic HFmrEF in SR in order to reduce the risk of all-cause and $\mathrm{CV}$ death ${ }^{14}$. Similar improvements in LVEF were seen for those in AF, but this did not translate into better outcomes with BBs for patients in AF. So far, there is no proof for beneficial effects of $\mathrm{BBs}$ on better outcomes of patients with HFmrEF and AF (ref. ${ }^{3}$ ). In a recent meta-analysis of randomized controlled trials, no clear beneficial effect of BBs on heart failure severity in HFpEF patients was found. However, BBs were found to be possibly beneficial in HFpEF patients with coronary artery disease (CAD) or AF (ref..$\left.^{15}\right)$. Due to the nature of the registry data we are unable to specify the etiology of HF in our patients ${ }^{16}$. Also, the data from echocardiography and/or coronary angiography are not available within the patient database. We could extrapolate data from other databases (e.g. the Czech FAR-NHL registry) but they do not contain all HF patients in the whole country and thus could be linked with a serious bias. The majority of patients in our analysis (77.9\% of HF patients in 2018) had CAD and only $10 \%$ of patients had a cardiomyopathy in their diagnoses. This does not mean that patients with CAD had a disease significant enough to explain the development of $\mathrm{HF}$ ( ref. $^{17-19}$ ). These numbers are different from the HF registries (e.g. $42.9 \%$ of HF patients with CAD and $29.5 \%$ with idiopathic dilated cardiomyopathy in the ESC-HF Long-Term Registry; $50.1 \%$ of HF patients with $\mathrm{CAD}$ and $41.6 \%$ with idiopathic dilated cardiomyopathy in the Czech FAR-NHL Registry) (ref. ${ }^{4,20}$ ). When compared to the data from the large registries, the difference in the number of cardiomyopathy diagnoses is striking. A possible explanation could be under-reporting of a cardiomyopathy diagnosis in our database and thus the data about HF etiology should be taken with caution. In our registry, more than $60 \%$ of HF patients had a history of arrhythmias, mostly AF (49.7\% of HF patients in 2018). $\mathrm{AF}$ was thus also far more prevalent when compared to the ESC-HF Long-Term Registry (21.5\% of HF patients) and FAR-NHL registry (34.8\% of HF patients) (ref., ${ }^{4,20}$ ). However, the fact that almost a half of the patients had a history of AF does not mean that they were in $\mathrm{AF}$ all the time. In fact, only one AF paroxysm in the patients' history was enough for the diagnosis. 
This is a general analysis of a real common practice and since some important data (LVEF, type of cardiomyopathy and the burden of AF) are missing, any comparisons with registries (that have however only a limited number of selected patients) should be taken with caution. Nevertheless, the fact that pharmacotherapy was analyzed in all patients in the country outweighs this limitation. Despite the fact, that we have found only slightly lower amount of drug prescription in comparison with specific heart failure registries, there is still a room for improvement in the pharmacotherapy of chronic HF.

\section{Study limitations}

A large number of patients in our database diminish the chance of selection bias. On the other hand, it inevitably leads to a low detail of individual patients' data. Data from echocardiography, ECG and laboratory samples are missing entirely. We can't rule out a population bias since all patients were diagnosed and treated in one developed country with highly advanced healthcare. Individual patient records might be filled out imperfectly. These potential imperfections should not have an impact on the pharmacology analysis. There is no single classification system for the causes of $\mathrm{HF}$, with much overlap between potential categories. This makes a precise assessment of a single diagnosis of HF in such a database challenging.

\section{CONCLUSION}

In an analysis of beta-blockers utilization in all patients treated for heart failure in the given year in the whole country, we have found only slightly lower amount of drug prescription in comparison with specific heart failure registries. This indicates a good translation of current standard of care into common clinical practice. Metoprolol remained the mostly prescribed drug. The prescription of bisoprolol and nebivolol has increased at the expense of carvedilol.

Acknowledgements: This study has been implemented to the Czech Republic national action plan of cardiovascular prevention. The project aims for the early and systematic detection of patients with CV risks connected with the effective treatment intervention. The long-term goal of the project is the $5 \%$ reduction of CV mortality during the next 10 years. This work was supported by the Czech Society of Cardiology via the Czech Republic National action plan of cardiovascular prevention.

Author contributions: MT, TS: literature search, manuscript concept and writing, data analysis, final approval; RA, ML, LP, JD, JP, AS, VG, MV: data analysis. Conflict of interest statement: None declared.

\section{REFERENCES}

1. Kotecha D, Flather MD, Altman DG, Holmes J, Rosano G, Wikstrand J, Packer M, Coats AJS, Manzano L, Bohm M, van Veldhuisen DJ, Andersson B, Wedel H, von Lueder TG, Rigby AS, Hjalmarson A, Kjekshus J, Cleland JGF; Beta-Blockers in Heart Failure Collaborative
G. Heart rate and rhythm and the benefit of beta blockers in patients with heart failure. J Am Coll Cardiol 2017;69:2885-96.

2. Von Lueder TG, Kotecha D, Atar D, Hopper I. Neurohormonal blockade in heart failure. Cardiac Fail Rev 2017;3:19-24.

3. Cleland JG. Beta-blockers for heart failure with reduced, mid-range, and preserved ejection fraction: an individual patient-level analysis of double-blind randomized trials. Eur Heart J 2018;39:26-35.

4. Spinar J, Spinarova L, Malek F, Ludka O, Krejci J, Ostadal P, Vondrakova D, Labr K, Spinarova M, Pavkova Goldbergova M, Benesova K, Jarkovsky J, Parenica J. Prognostic value of NT-proBNP added to clinical parameters to predict two-year prognosis of chronic heart failure patients with mid-range and reduced ejection fraction-A report from FAR NHL prospective registry. PloS One 2019;14(3):e0214363. doi: $10.1371 /$ journal.pone.0214363

5. Spinar J, Jarkovsky J, Spinarova L, Mebazaa A, Gayat E, Vitovec J. AHEAD score-Long-term risk classification in acute heart failure. Int J Cardiol 2016;202:21-26.

6. Lund LH, Carrero JJ, Farahmand B, Henriksson KM, Jonsson $\AA$, Jernberg T, Dahlström U. Association between enrolment in a heart failure quality registry and subsequent mortality - a nationwide cohort study. Eur Heart J 2017;19(9),1107-16.

7. Ponikowski P, Voors AA, Anker SD, Bueno H, Cleland JGF, Coats AJS, Falk V, González-Juanatey JR, Harjola VP, Jankowska EA, Jessup M, Linde C, Nihoyannopoulos P, Parissis JT, Pieske B, Riley JP, Rosano GMC, Ruilope LM, Ruschitzka F, Rutten FH, van der Meer P; ESC Scientific Document Group. 2016 ESC Guidelines for the diagnosis and treatment of acute and chronic heart failure: The Task Force for the diagnosis and treatment of acute and chronic heart failure of the European Society of Cardiology (ESC). Developed with the special contribution of the Heart Failure Association (HFA) of the ESC. Eur Heart J 2016;37(27):2129-2200.

8. Špinar J, Hradec J, Špinarová L, Vítovec J. Souhrn Doporučených postupů ESC pro diagnostiku a léčbu akutního a chronického srdečního selhání z roku 2016. Cor et Vasa 2016;58(5):e530-e568. (In Czech)

9. Spinar J, Vítovec J, Spinarová L. Pharmacotherapy of chronic heart failure after the first decade of 21 st century. Vnitr Lek 2011;57(11):959-65. (In Czech)

10. Goldstein S, Fagerberg B, Hjalmarson A, Kjekshus J, Waagstein F, Wedel H, Wikstrand J. Metoprolol controlled release/extended release in patients with severe heart failure: analysis of the experience in the MERIT-HF study. J Am Coll Cardiol 2001;38:932-38.

11. Kotecha D, Holmes J, Krum H, Altman DG, Manzano L, Cleland JGF, Lip GYH, Coats AJS, Andersson B, Kirchhof P, von Lueder TG, Wedel H, Rosano G, Shibata MC, Rigby A, Flather MD. Effificacy of b blockers in patients with heart failure plus atrial fifibrillation: an individualpatient data meta-analysis. Lancet 2014;384:2235-43.

12. Melenovsky V, Hwang SJ, Lin G, Redfield MM, Borlaug BA. Right heart dysfunction in heart failure with preserved ejection fraction. Eur Heart J 2014;21;35(48):3452-62.

13. Vítovec J, Spinar J. Beta-blockers in the treatment of chronic heart failure. How should results of clinical studies be introduced into clinical practice. Vnitr Lek 2000;46(3):161-65. (In Czech)

14. Seferovic PM, Ponikowski P, Anker SD, Bauersachs J, Chioncel O, Cleland JGF, de Boer RA, Drexel H, Ben Gal T, Hill L, Jaarsma T, Jankowska EA, Anker MS, Lainscak M, Lewis BS, McDonagh T, Metra M, Milicic D, Mullens W, Piepoli MF, Rosano G, Ruschitzka F, Volterrani M, Voors AA, Filippatos G, Coats AJS. Clinical practice update on heart failure 2019: pharmacotherapy, procedures, devices and patient management. An expert consensus meeting report of the Heart Failure Association of the European Society of Cardiology. Eur J Heart Fail 2019;21(10):1169-86.

15. Fukuta H, Goto T, Wakami K, Kamiya T, Ohte N. Effect of beta-blockers on heart failure severity in patients with heart failure with preserved ejection fraction: a meta-analysis of randomized controlled trials. Heart Fail Rev 2020; Aug 3. doi: 10.1007/s10741-020-10013-5 (Epub ahead of print)

16. Špinar J, Vítovec J, Špinarová L. Heart Failure With Preserved Ejection Fraction. Vnitr Lek 2016;62(7-8),646-51. (In Czech)

17. Spinarová L, Spinar J, Vítovec J. Pharmacotherapy following myocardial infarction. Vnitr Lek 2011;57(11),966-69. (In Czech)

18. Spinar J, Vítovec J, Spinarová L; Zastoupení resitelů studie FARIM. FARIM - FARmakoterapie po Infarktu Myokardu [FARIM FARmakoterapie po Infarktu Myokardu (Post-Myocardial Infarction Pharmacotherapy Study)]. Vnitr Lek 2011;57(9):778-84. (In Czech) 
19. Vítovec J, Špinarová L, Špinar J. Sekundární prevence po infarktu myokardu-režimové a farmakologické postupy. Interni Med 2011;13(5),202-4. (In Czech)

20. Chioncel O, Lainscak M, Seferovic PM, Anker SD, Crespo-Leiro MG, Harjola VP, Parissis J, Laroche C, Piepoli MF, Fonseca C, Mebazaa A Lund L, Ambrosio GA, Coats AJ, Ferrari R, Ruschitzka F, Maggioni AP Filippatos $\mathrm{G}$. Epidemiology and one-year outcomes in patients with chronic heart failure and preserved, mid-range and reduced ejection fraction: an analysis of the ESC Heart Failure Long-Term Registry. Eur J Heart Fail 2017;19(12):1574-85. 